\title{
Spirulina platensis Protein Ekstraktları ile Zenginleştirilmiş Buğday Unundan Üretilen Hamurun Reolojik ve Teknofonksiyonel Özelliklerinin Araştırılması
}

\author{
Meltem Y1lmaz, Aysun Yücetepe* \\ Aksaray University, Faculty of Engineering, Departmant of Food Engineering, Aksaray, Turkey, (ORCID: 0000-0003-2543-4166), mltm.ylmz.14@gmail.com \\ *Aksaray University, Faculty of Engineering, Departmant of Food Engineering, Aksaray, Turkey, (ORCID: 0000-0002-3800-4774), aysunyucetepe@aksaray.edu.tr
}

(Illk Geliş Tarihi 13 Temmuz 2021 ve Kabul Tarihi 7 Kasım 2021)

(DOI: $10.31590 /$ ejosat.970720)

ATIF/REFERENCE: Yılmaz, M., Yucetepe, A. (2021). Spirulina platensis protein ekstraktları ile zenginleştirilmiş buğday unundan üretilen hamurun reolojik ve teknofonksiyonel özelliklerinin araştırılması. Avrupa Bilim ve Teknoloji Dergisi, (27), 768-775.

$\ddot{\mathbf{O z}}$

Spirulina platensis, simbiyotik, çok hücreli ve ipliksi yapıda mavi-yeşil bir mikroalgdir. Esansiyel amino asitler, $\beta$-karoten, fikobiliproteinler gibi pigmetler ve eikosapentaenoik asit (EPA) ve dokosaheksaenoik asit (DHA) gibi çoklu doymamış yağ asitleri gibi bazı değerli biyoaktif moleküller açısından zengindir. Ayrıca, yüksek protein içeriği (kuru ağırlıkta \%60-70) ile önemli protein kaynaklarından biridir. Bu çalışmada, buğday ununun Spirulina platensis ve Spirulina platensis'den ultrases destekli ekstraksiyon ile ekstrakte edilen protein ekstraktları ile zenginleştirilmesi ve zenginleştirilen unların reolojik ve teknofonksiyonel özelliklerinin araştırılması gerçekleştirilmiştir. Çalışmanın sonuçlarına göre, farklı oranlarda Spirulina platensis tozu (SP) ve Spirulina platensis protein ekstraktları (SPE) ile zenginleştirilen buğday ununun ekstensograf analizleri sonucunda en uygun SP ve SPE oranları \%0,125, 0,25 ve 0,5 olarak belirlenmiştir. Farinograf analizi sonuçlarına göre, SP-\% 0,5 'in en yüksek su absorpsiyonu (\%57,1) değerine sahip olduğu belirlenmiştir $(\mathrm{p}<0,05)$. Örneklerin normal sedimentasyon, gecikmeli sedimentasyon, yaş glüten, kuru gluten ve gluten indeksi değerleri arasındaki farklılık önemli değilken ( $\mathrm{p} \geq 0,05), \% 0,125$ oranında SPE ile zenginleştirilen un örneklerinin su tutma kapasitesi $(\% 108,68)$ diğer örneklerden istatiksel olarak önemli düzeyde daha yüksektir $(\mathrm{p}<0,05)$.

Anahtar Kelimeler: Spirulina platensis, buğday unu, ekstensograf, farinograf, reolojik özellikler, su tutma kapasitesi, zenginleştirme.

\section{Investigation of Rheological and Techno-functional Properties of Wheat Flour Enriched with Spirulina platensis Protein Extracts}

\begin{abstract}
Spirulina platensis is a simbiotic, multicellular and filamentous blue-green microalgae. It is rich in terms of essential amino acids, pigments such as $\beta$-caroten and phycobiliproteins, polyunsaturated fatty acids such as eicosapentaenoic acid (EPA) and docosahexaenoic acid (DHA). Moreover, it is one of important protein sources with high protein content (60-70\% in dry weight). Enrichment of wheat flour with Spirulina platensis and Spirulina platensis protein extracts obtained by ultrasound-assisted extraction and investigation of rheological and techno-functional properties of the flours were carried out in the present study. According to the results of extensograph analysis of the enriched flours with Spirulina platensis powder (SP) and protein extracts from Spirulina platensis (SPE), the best ratios for SP and SPE were determined as $0.125 \%, 0.25 \%$ and $0.5 \%$. The SP-0.5\% had the highest water absorption capacity $(57.1 \%)(\mathrm{p}<0.05)$. Water absorption capacity of the enriched flours with $0.125 \%$ SPE was higher than the others $(\mathrm{p}<0.05)$, while differences among normal sedimentation, delayed sedimentation, wet gluten, dry gluten and gluten index were not significant $(\mathrm{p} \geq 0.05)$.
\end{abstract}

Keywords: Spirulina platensis, wheat flour, extensograph, farinograph, rhelogical properties, water absorption capacity, enrichment.

*Sorumlu Yazar: aysunyucetepe@aksaray.edu.tr, aysunyucetepe@gmail.com 


\section{Giriş}

Spirulina platensis mikroalgi yüksek protein içeriği ve besinsel özelliklerinden dolayı antik zamanlarda Afrika ve Meksika toplumları tarafindan, günümüzde ise hemen hemen tüm dünya ulusları tarafindan tüketilen Oscillatoriaceae ailesine ait, çok hücreli, simbiyotik ve ipliksi yapıda mavi-yeşil bir mikroalgdir (Estrada ve ark., 2001). Yüksek pH'ya $(8,5-11,0)$ sahip tuzlu sularda $(>30 \mathrm{~g} / \mathrm{l})$ ve yüksek solar radyasyon seviyelerine sahip alanlarda daha fazla gelişim göstermektedir. Spirulina platensis önemli bir doğal protein kaynağı (kuru ağırlıkta \%60-70) olmakla birlikte omega-3 ve omega-6 çoklu doymamış yă asitleri, esansiyel amino asitler, mineraller, vitaminler, antioksidatif aktiviteye sahip pigmentler ve polisakkaritler içermektedir (Wang ve ark., 2007, ChamorroCevallos ve ark., 2008, Bermejo ve ark., 2008, Gad ve ark., 2011, El-Tantawy, 2015, Vo ve ark., 2016, Pelizer ve ark., 2015).

Gıdaların zenginleştirilmesi, gıda ürünlerine besinsel özelliklerini iyileştirmek amacıyla protein ya da mikro besin öğeleri gibi zengin gida kaynaklarının ilave edilmesi ile gerçekleştirilmektedir. Bu noktada yüksek protein içeriği nedeni ile Spirulina platensis'in çeşitli gıda ürünlerinin zenginleştirilmesi amacıyla kullanıldığı bilinmektedir (Ak ve ark., 2016, Lee ve ark., 2011). Le ve ark. (2011)'nın çalışmasında, farklı oranlardaki Spirulina platensis ile üretilen fonksiyonel ekmeklerin depolama süresince nem miktarı, tekstürel, duyusal ve renk özellikleri araştırılmıştır. Konu ile ilgili yapılmış diğer çalışmalar incelendiğinde, süt ürünleri, bisküvi, makarna ve çeşitli ekmeklerin protein içeriklerinin arttırılması amacıyla, Spirulina platensis ve Spirulina platensis'den elde edilen proteinler ile zenginleştirildiği görülmektedir (Stanic-Vucinic ve ark., 2018). El Baky ve ark. (2015)'nın yaptığı çalışmada ise Spirulina platensis'den elde edilen saflaştııılmış fikosiyanin ile bisküvi ürünleri zenginleştirilmiştir.

Buğday ununun besinsel özelliklerinin yanı sıra reolojik özellikleri de son ürün özelliklerine etkileri bakımından önem taşımaktadır. Unun reolojik özelliklerinin belirlenmesi için kullanılan cihazlardan olan ekstensograf cihazı, hamurun firınlanma ve ekmeğe dönüşüm davranışı hakkında fikir veren ve hamurun esneme özelliğinin ölçülmesine imkan sağlayan bir cihazdir (Abbasi ve ark., 2012). Bu cihazlar, hamurun uzamaya karş1 gösterdiği direnç ve esneyen hamurun kopmadan önce uzadığı mesafeyi kaydetmektedir. Unun reolojik özelliklerinin belirlenmesi için kullanılan diğer bir cihaz olan farinograf cihazı ise hamurun mekaniksel davranışlarını değerlendirmek için kullanılmaktadır (Sarker ve ark., 2008). Farinograf ölçüm ile unun su tutma kapasitesinin belirlenmesinin yanı sıra, hamurun kıvamı ve gluten proteininin dayanımı da tahminlenmektedir (Ram ve ark., 2005).

Sunulan çalışma kapsamında öncelikle Spirulina platensis mikroalginden ultrases destekli ekstraksiyon ile protein ekstraksiyonu gerçekleştirilmiştir. Daha sonra, Spirulina platensis tozu (SP) ve Spirulina platensis'den elde edilen protein ekstraktları (SPE) buğday ununa üç farklı oranda katılarak hazırlanan un örneklerinin reolojik ve teknofonksiyonel özellikleri araştırılmıştır.

\section{Materyal ve Metot}

\subsection{Materyal}

Spirulina platensis tozu Akuatik Su Ürünleri, Gıda, Tohum, Kozmetik, Danışmanlık, Mühendislik San. ve Tic. Ltd. Şti. (Adana, Türkiye) isimli firmadan temin edilmiştir. Buğday unu, Türk Gida Kodeksi Buğday Unu Tebliği'ne uygun olarak üretilen Tip 2 ekmeklik buğday unu Çandaroğulları Derya Un ve Yem San. Tic. Ltd. Şti. (Manisa, Türkiye) firmasından satın alınmıştır. Hidrokrolik asit, sodyum hidroksit ve hekzan Sigma-Aldrich Chemie GmbH'den (Steinheim, Almanya) temin edilmiştir.

\subsection{Metot}

\subsubsection{Spirulina platensis'ten proteinlerin ultrases destekli ekstraksiyonu}

Spirulina platensis'ten proteinlerin ekstraksiyonu için Benelhadj ve ark. (2016) ile Yucetepe ve ark. (2018)'nın metotları kullanılmıştır. Öncelikle örneklerdeki yağ fraksiyonları Stone ve ark. (2015)'nın yöntemi kullanılarak uzaklaştırılmıştır. Yağ fraksiyonları uzaklaştıııldıktan sonra, 1 gram Spirulina platensis tozuna $15 \mathrm{ml}$ distile su eklenmiş ve 60 dakika boyunca oda sıcaklığında manyetik karıştırıcıda karıştırılmış̧ır. Karışımın pH's $0,1 \mathrm{~N} \mathrm{NaOH}$ kullanılarak 8,0'e ayarlandıktan sonra, karışım ultrases su banyosuna konularak $4{ }^{\circ} \mathrm{C}$ 'de 60 dakika boyunca tutulmuştur. Ultrases uygulamasından sonra, $45^{\circ} \mathrm{C}$ sicaklıktaki su banyosunda $65 \mathrm{rpm}$ çalkalama hızında 2 saat boyunca ekstraksiyon işlemi gerçekleştirilmiştir. Daha sonra $4000 \mathrm{rpm}$ 'de $4{ }^{\circ} \mathrm{C}$ 'de 30 dakika boyunca santrifüj edildikten sonra, süzüntü alınmıș ve $\mathrm{pH}$ değeri Spirulina platensis proteinlerinin izoelektrik noktasi olan 3,0'e ayarlanmıştır. Örnekler tekrar 4000 rpm'de 4 ${ }^{\circ} \mathrm{C}$ 'de 30 dakika boyunca santrifüj işlemine tabi tutulmuş ve çöken kısım alınarak liyofilize edilmiştir. Liyofilize edilen Spirulina platensis protein ekstraktları oksijen ve 1şık almayacak şekilde ambalajlanarak, analizlere kadar $+4{ }^{\circ} \mathrm{C}$ 'de muhafaza edilmiştir.

\subsubsection{Kontrol ve SP ve SPE ilaveli unların bazı fizikokimyasal ve reolojik özelliklerinin belirlenmesi}

Kontrol grubunda ve Spirulina platensis tozu ve Spirulina platensis'ten elde edilen protein ekstraktları ilave edilmiş un örneklerinde Zeleny sedimantasyon değeri belirlenmiştir (Zelleny,1947). Ayrıca Brabender farinograf analizleri AACC 5421'e göre, ekstensograf analizleri AACC 54-10'a göre gerçekleștirilmiştir (AACC, 2000). Yaş gluten miktarı ve gluten indeksi AACC metot no: 38-21A (AACC, 2000)'a göre, kuru gluten miktarı ise Özkaya (2005)'ya göre belirlenmiştir.

Çalışmamızda, Spirulina platensis tozu ve Spirulina platensis'den elde edilen protein ekstraktları ile zenginleştirilmiş un üretmek için en uygun SP ve SPE oranların belirlemek amacıyla öncelikle buğday ununa $\% 5,10$ ve 15 oranlarında SP katılarak ekstensograf ölçümleri gerçekleştirilmiştir. Daha sonra $\% 0,25, \% 0,5, \% 0,75$ ve $\% 1$ oranlarında SP ve son olarak $\% 0,125$, 0,25 ve 0,5 oranlarında SP ve SPE katılarak hazırlanan un örneklerinin ekstensograf ve farinograf analizleri gerçekleştirilmiştir. 


\subsubsection{Kontrol ve SP ve SPE ilaveli unların bazı teknofonksiyonel özelliklerinin belirlenmesi}

\subsubsection{Yığın yoğunluğunun belirlenmesi}

Un örneklerinin yığın yoğunluğu Giami ve Bekebain (1992)'nın metoduna göre belirlenmiştir. Kalibre edilmiş santrifüj tüplerinin darası alındıktan sonra $5 \mathrm{ml}$ hacim seviyesine kadar örnek konulmuş ve tartım yapıldıktan sonra, aşağıdaki eşitlik kullanılarak un örneklerinin yığın yoğunluğu hesaplanmıştır.

$$
\text { Yığın yoğunluğu, g/ml }=\frac{\text { Örnek ağırlığı, g }}{\text { Örnek hacmi, ml }}
$$

\subsubsection{Su tutma kapasitesi}

Örneklerin su tutma kapasitesi De Marco ve ark. (2014) ve Giami ve Bekebain (1992)'nin metoduna göre belirlenmiştir. Bir gram un örneği ile $10 \mathrm{ml}$ distile su, $20 \mathrm{ml}$ 'lik santrifüj tüplerinde vorteks cihazı kullanılarak 2 dakika boyunca karıştırılmış ve karışım oda sıcaklığında 30 dakika boyunca bekletilmiştir. Daha sonra, 4100 rpm'de 20 dakika boyunca uygulanan santrifüj işleminden sonra süzüntü uzaklaştırılmış ve çökeltiyi içeren santrifüj tüpleri tartılmıştır. Örneklerin su tutma kapasitesini hesaplamak için aşağıdaki eşitlik kullanılmıştır:

$$
\text { Su tutma kapasitesi, } \%=\frac{A-B}{C} \times 100
$$

A: Tüp ve çökeltinin ağırlıkları toplamı, B: Tüp ve kuru örneğin ağırlıkları toplamı, C: Kuru örneğin ağırlığı.

\subsubsection{Yă̆ tutma kapasitesi}

Örneklerin yağ tutma kapasitesi De Marco ve ark. (2014) ve Giami ve Bekebain (1992)'nin metoduna göre belirlenmiştir. Bir gram un örneği ile $10 \mathrm{ml}$ ayçiçek yağı $20 \mathrm{ml}$ 'lik santrifüj tüplerinde vorteks cihazı kullanılarak 2 dakika boyunca karıştırılmış ve karışım oda sıcaklığında 30 dakika boyunca bekletilmiştir. Daha sonra 4100 rpm'de 20 dakika boyunca uygulanan santrifüj işleminden sonra süzüntü uzaklaştırılmış ve çökeltiyi içeren santrifüj tüpleri tartılmıştır. Örneklerin yağ tutma kapasitesini hesaplamak için aşağıdaki eşitlik kullanılmıştır:

$$
\text { Yağ tutma kapasitesi, } \%=\frac{\mathrm{A}-\mathrm{B}}{\mathrm{C}} \times 100
$$

A: Tüp ve çökeltinin ağırlıkları toplamı, B: Tüp ve kuru örneğin ağırlıkları toplamı, C: Kuru örneğin ağırlığı.

\subsubsection{4 Şişme indeksi}

Örneklerin şişme indeksi değeri Onuegbu ve ark. (2013)'nın metoduna göre belirlenmiştir. Her bir un numunesinin şişme indeksi, her numunenin bir birim ağırlığının şişmiş hacminin, dereceli bir ölçüm silindirindeki başlangıç hacmine oranı olarak belirlenmiştir. Her bir un örneğinden 1'er gram alınarak 20 ml'lik silindire konulmuş ve üzerine $10 \mathrm{ml}$ distile su eklenmiştir. Örnek hacmi kaydedildikten sonra, karışım 1 saat boyunca bekletilmiş ve hacim tekrar kaydedilmiştir. Un örneklerinin şişme indeksi aşağıdaki formül kullanılarak hesaplanmıştır.
Şişme indeksi $=\frac{\text { Örneklerin başlangıç hacmi }}{\text { Örneklerin şişme sonrası hacmi }}$

\section{4. İstatistiksel analiz}

Deney sonuçları Minitab İstatistik Programı (Minitab, Version 17, Minitab Inc., State College, Pensilvanya, ABD) kullanılarak analizlenmiştir. Değerler arasındaki farklılık $(\mathrm{p}<$ 0,05) Tukey testi ile belirlenmiştir.

\section{Sonuç ve Tartışma}

\subsection{Kontrol ile SP ve SPE ilaveli unların reolojik özellikleri}

Çalıșmanın bu kısmında kontrol ve SP ve SPE ilaveli unlar ile hazırlanan hamurların ekstensograf ve farinograf analizleri gerçekleştirilerek reolojik özellikleri araştırılmıştır. Ekstensograf analiz ile dinlenme süreleri olarak adlandırılan 45., 90. ve 135. dakikalarda hamurun reolojik davranışlarındaki değişimler ölçülmektedir. Hamurda zamanla meydana gelen bu değişimler ya unun biyokimyasal aktivitesi gibi iç faktörler ya da una katılan çeşitli katkı maddelerinden kaynaklanan dış faktörler nedeni ile oluşmaktadır (Miś ve ark., 2012). Un örneklerinin ekstensograf analizinde; hamurun uzamaya karşı gösterdiği maksimum direnç $\left(\mathrm{R}_{\text {maks }}\right)$, hamurun sabit deformasyondaki direnci $\left(\mathrm{R}_{5}\right)$, esneklik, işlenebilirlik oranı, maksimum işlenebilirlik oranı ve enerji değerleri elde edilmektedir (Burešová ve ark., 2014). Çalışmamızda, Spirulina platensis tozu ve Spirulina platensis'den elde edilen protein ekstraktları ile zenginleştirilmiş un üretmek için en uygun SP ve SPE oranlarını belirlemek amacıyla öncelikle una \%5, 10 ve 15 oranlarında SP katılarak ekstensograf ölçümleri gerçekleştirilmiştir (Tablo 1). Tablo 1'de verilen 135. dakikadaki ekstensograf verilerine göre, kontrol örneklerine ait esneklik değeri hariç tüm değerler zenginleştirilmiş unlara ait değerlerden istatistiksel olarak önemli düzeyde daha yüksektir $(\mathrm{p}<0,05)$. Bu nedenle, $\% 5,10$ ve 15 oranlarında zenginleştirilmiş unların ekstensograf ile elde edilen değerleri kontrole göre daha düşük kaldığından, daha düşük SP oranları $(\% 0,25, \% 0,5, \% 0,75$ ve $\% 1)$ ile zenginleştirilmiş un örnekleri hazırlanarak, ekstensograf ölçümleri gerçekleştirilmiştir (Tablo 2). Tablo 2'de görüldüğü gibi, $\% 0,75$ ve $\% 1,0$ oranlarında Spirulina platensis katılarak zenginleştirilen unların 135. dakika ekstensograf verilerinde enerji ve esneklik değerleri hariç diğer değerlerin kontrol örneğinden önemli düzeyde düşük olduğu görülmektedir $(\mathrm{p}<0,05)$. Ayrıca, SP \%0,25 enerji ve esneklik değerleri ve SP \%0,5'in esneklik değeri kontrolden daha yüksektir. Bu nedenle bir sonraki un formulasyonunda SP oranları $\% 0,125,0,25$ ve 0,5 olarak belirlenerek ekstensograf ölçümleri gerçekleştirilmiştir (Tablo 3). Belirlenen değer aralıklarında yapılan ekstensograf analizleri sonucunda, 135. dakikada kontrol örneği ile Spirulina platensis ile zenginleştirilmiş unlar kıyaslandığında, ekstensogram parametreleri arasında önemli düzeyde bir farklılık olmadığ $(p \geq 0,05)$ ve SP ve SPE ilavesinin unların reolojik özelliklerini olumsuz yönde etkilemediği görülmüştür (Tablo 4). Bu nedenle SP ve SPE ile zenginleştirilmiş un elde etmek için, unlara $\% 0,125,0,25$ ve 0,5 oranlarında Spirulina platensis tozu ve Spirulina platensis protein ekstraktları katılmıştır ve hazırlanan SP ve SPE ilaveli unlara sonraki analizler uygulanmıştır.

Farinograf analizler ile unun hamur haline gelmesi sırasında unun su absropsiyonu ve hamurun gelişme süresi, stabilite ve 
yumuşama derecesi değerleri üzerinden hamurun kıvamı hakkında bilgiye ulaşılabilmektedir (Stojceska ve Butler, 2008). Özellikle gelişme süresi değerinin, undaki protein kalitesinin belirlenmesinde kullanıldığı bilinmektedir (Karababa ve Ozan, 1998). Çalışmamızda, kontrol örneği ve $\% 0,125,0,25$ ve 0,5 oranlarında SP ve SPE içeren un örneklerinin farinogram değerleri Tablo 5'de gösterilmiştir. Unların gelişme süresi, stabilite değeri ve yumuşama derecesi bakımından istatistiksel olarak önemli düzeyde bir farklılık oluşmamıştır $(\mathrm{p} \geq 0,05)$. Tablo 5 'de görüldüğü gibi, SPE \%0,5'in su absorpsiyonu $(\% 57,1 \pm 0,0)$ en yüksek $(p<0,05)$ düzeyde gerçekleşmiştir. Farinograf su tutma kapasitesi değeri, ekmek üretimi için hamurun su gereksinimini değerlendirmek amacıyla kullanılmaktadır (Ram ve ark., 2005). Rothkaehl (2004)'e göre unların \%50-57 arasındaki farinogram su tutma kapasitesi iyi kalitede, \%58-60 arasındaki su tutma kapasitesi değeri çok iyi kalitede un olduğunu göstermektedir.

Tablo 1. Spirulina platensis tozunun \%5, 10 ve 15 oranlarında ilave edildiği buğday unlarının 45, 90 ve 135. dakikalarda ekstensogram dĕgerleri.

\begin{tabular}{|c|c|c|c|c|c|c|}
\hline Örnek & Enerji, $\left(\mathrm{cm}^{2}\right)$ & R5 (B.U.)* & $\begin{array}{c}\text { Esneklik } \\
\text { (mm) }\end{array}$ & Rmaks (B.U.) & $\begin{array}{c}\text { İşlenebilirlik } \\
\text { Oranı } \\
\text { (B.U./mm) } \\
\end{array}$ & $\begin{array}{c}\text { Maksimum } \\
\text { İşlenebilirlik } \\
\text { Oranı (B.U./mm) } \\
\end{array}$ \\
\hline \multicolumn{7}{|c|}{ 45. dakika } \\
\hline Kontrol & $66,0 \pm 1,0^{\mathrm{a}^{*}}$ & $252,5 \pm 4,5^{\mathrm{a}}$ & $152,0 \pm 0,0^{\mathrm{a}}$ & $306,0 \pm 6,0^{\mathrm{a}}$ & $1,7 \pm 0,1^{\mathrm{ab}}$ & $2,1 \pm 0,1^{\mathrm{ab}}$ \\
\hline SP-\%5 & $50,0 \pm 2,0^{\mathrm{b}}$ & $220,0 \pm 13,0^{\mathrm{a}}$ & $139,0 \pm 0,0^{\mathrm{b}}$ & $236,5 \pm 11,5^{b}$ & $1,6 \pm 0,1^{b}$ & $1,7 \pm 0,1^{b}$ \\
\hline SP-\%10 & $42,5 \pm 0,5^{\text {bc }}$ & $218,5 \pm 0,5^{\mathrm{a}}$ & $125,5 \pm 1,5^{\mathrm{c}}$ & $218,5 \pm 0,5^{\mathrm{b}}$ & $1,8 \pm 0,1^{\mathrm{ab}}$ & $1,8 \pm 0,1^{\mathrm{b}}$ \\
\hline SP-\%15 & $40,0 \pm 2,0^{\mathrm{c}}$ & $266,0 \pm 19,0^{\mathrm{a}}$ & $102,5 \pm 2,5^{\mathrm{d}}$ & $271,5 \pm 19,5^{\mathrm{ab}}$ & $2,6 \pm 0,2^{\mathrm{a}}$ & $2,7 \pm 0,3^{\mathrm{a}}$ \\
\hline \multicolumn{7}{|c|}{ 90. dakika } \\
\hline Kontrol & $65,5 \pm 2,5^{\mathrm{a}}$ & $256,5 \pm 1,5^{\mathrm{a}}$ & $145,0 \pm 3,0^{\mathrm{a}}$ & $323,5 \pm 9,5^{\mathrm{a}}$ & $1,8 \pm 0,1^{\mathrm{a}}$ & $2,3 \pm 0,1^{\mathrm{a}}$ \\
\hline SP-\%5 & $39,0 \pm 2,0^{\mathrm{b}}$ & $187,0 \pm 11,0^{\mathrm{b}}$ & $133,5 \pm 0,5^{\mathrm{a}}$ & $189,5 \pm 10,5^{\mathrm{b}}$ & $1,4 \pm 0,1^{\mathrm{a}}$ & $1,4 \pm 0,1^{\mathrm{b}}$ \\
\hline SP-\%10 & $27,5 \pm 1,5^{\mathrm{b}}$ & $160,0 \pm 6,0^{\mathrm{b}}$ & $114,5 \pm 3,5^{\mathrm{b}}$ & $170,5 \pm 5,5^{\mathrm{b}}$ & $1,4 \pm 0,0^{\mathrm{a}}$ & $1,5 \pm 0,0^{\mathrm{b}}$ \\
\hline SP-\%15 & $28,5 \pm 0,5^{b}$ & $188,0 \pm 8,0^{\mathrm{b}}$ & $101,5 \pm 2,5^{\mathrm{b}}$ & $212,5 \pm 8,5^{\mathrm{b}}$ & $1,9 \pm 0,2^{\mathrm{a}}$ & $2,1 \pm 0,1^{\mathrm{a}}$ \\
\hline \multicolumn{7}{|c|}{ 135. dakika } \\
\hline Kontrol & $71,5 \pm 2,5^{\mathrm{a}}$ & $298,0 \pm 1,0^{\mathrm{a}}$ & $140,5 \pm 3,5^{\mathrm{a}}$ & $372,5 \pm 3,5^{\mathrm{a}}$ & $2,2 \pm 0,1^{\mathrm{a}}$ & $2,7 \pm 0,1^{\mathrm{a}}$ \\
\hline SP-\%5 & $27,0 \pm 3,0^{\mathrm{b}}$ & $136,5 \pm 14,5^{b}$ & $132,0 \pm 6,0^{\mathrm{a}}$ & $139,5 \pm 13,5^{\mathrm{b}}$ & $1,1 \pm 0,1^{\mathrm{b}}$ & $1,1 \pm 0,1^{\mathrm{b}}$ \\
\hline SP-\%10 & $16,5 \pm 0,5^{\mathrm{b}}$ & $99,5 \pm 4,5^{\mathrm{b}}$ & $105,5 \pm 0,5^{\mathrm{b}}$ & $129,0 \pm 7,0^{\mathrm{c}}$ & $1,0 \pm 0,1^{\mathrm{b}}$ & $1,2 \pm 0,1^{\mathrm{b}}$ \\
\hline SP-\%15 & $13,0 \pm 1,0^{\mathrm{b}}$ & $83,0 \pm 5,0^{\mathrm{b}}$ & $87,5 \pm 4,5^{\mathrm{b}}$ & $119,0 \pm 8,0^{\mathrm{d}}$ & $1,0 \pm 0,1^{\mathrm{b}}$ & $1,4 \pm 0,1^{\mathrm{b}}$ \\
\hline
\end{tabular}

SP: Spirulina platensis; B.U.: Brabender birimi; mm: milimetre. SP-\%5, SP-\%10 ve SP-\%15: Sirasıyla \%5, \%10 ve \%15 oranında SP ilaveli un. Değerlerin istatistiksel analizleri 45, 90 ve 135. dakikalar için ayrı olarak gerçekleştirilmiştir. *a, b, c harfleri 45, 90 ve 135 . dakikalardaki aynı sütun için istatistiksel olarak farklılığ ifade etmektedir ( $\mathrm{p}<0,05$, Tukey).

Tablo 2. Spirulina platensis tozunun \%0,25, 0,5, 0,75 ve 1 oranlarında ilave edildiği buğday unlarının 45, 90 ve 135 . dakikalarda ekstensogram değerleri.

\begin{tabular}{|c|c|c|c|c|c|c|}
\hline Örnek & Enerji, $\left(\mathrm{cm}^{2}\right)$ & R $_{5}$ (B.U.)* & $\begin{array}{l}\text { Esneklik, } \\
\text { (mm) }\end{array}$ & $\mathbf{R}_{\text {maks (B.U.) }}$ & $\begin{array}{c}\text { İşlenebilirlik } \\
\text { Oranı } \\
\text { (B.U./mm) }\end{array}$ & $\begin{array}{c}\text { Mak. } \\
\text { İşlenebilirlik } \\
\text { Oranı } \\
\text { (B.U./mm) }\end{array}$ \\
\hline \multicolumn{7}{|c|}{45 Dakika } \\
\hline Kontrol & $93,5 \pm 0,5^{\mathrm{a}^{*}}$ & $333,5 \pm 2,5^{\mathrm{a}}$ & $151,5 \pm 2,5^{\text {a }}$ & $455,0 \pm 16,0^{\mathrm{a}}$ & $2,2 \pm 0,1^{\mathrm{a}}$ & $3,0 \pm 0,2^{\mathrm{a}}$ \\
\hline SP-\%0,25 & $94,0 \pm 4,0^{\mathrm{a}}$ & $277,5 \pm 6,5^{\mathrm{c}}$ & $170,5 \pm 4,5^{\mathrm{a}}$ & $408,0 \pm 5,0^{\mathrm{ab}}$ & $1,6 \pm 0,0^{\mathrm{b}}$ & $2,4 \pm 0,0^{\mathrm{a}}$ \\
\hline SP- $\% 0,5$ & $83,0 \pm 5,0^{\mathrm{a}}$ & $292,0 \pm 1,0^{\mathrm{bc}}$ & $153,5 \pm 6,5^{\mathrm{a}}$ & $393,5 \pm 5,5^{b}$ & $1,9 \pm 0,1^{\mathrm{ab}}$ & $2,5 \pm 0,0^{\mathrm{a}}$ \\
\hline SP- $\% 0,75$ & $94,0 \pm 3,0^{\mathrm{a}}$ & $311,5 \pm 7,5^{\mathrm{ab}}$ & $160,5 \pm 0,5^{\mathrm{a}}$ & $429,0 \pm 14,0^{\mathrm{ab}}$ & $1,9 \pm 0,0^{\mathrm{ab}}$ & $2,7 \pm 0,1^{\mathrm{a}}$ \\
\hline SP-\%1,0 & $81,5 \pm 5,5^{\mathrm{a}}$ & $300,5 \pm 1,5^{\mathrm{bc}}$ & $151,0 \pm 8,0^{\mathrm{a}}$ & $388, \pm / 6,5^{\mathrm{b}}$ & $2,0 \pm 0,1^{\mathrm{ab}}$ & $2,6 \pm 0,1^{\mathrm{a}}$ \\
\hline \multicolumn{7}{|c|}{90 Dakika } \\
\hline Kontrol & $106,0 \pm 7,0^{\mathrm{a}}$ & $394,5 \pm 6,5^{\text {a }}$ & $147,5 \pm 5,5^{\mathrm{a}}$ & $537,0 \pm 23,0^{\mathrm{a}}$ & $2,6 \pm 0,1^{\mathrm{a}}$ & $3,6 \pm 0,0^{\mathrm{a}}$ \\
\hline SP- $\% 0,25$ & $95,5 \pm 4,5^{\mathrm{a}}$ & $315,0 \pm 24,0^{\mathrm{b}}$ & $159,0 \pm 12,0^{\mathrm{a}}$ & $454,5 \pm 22,5^{\mathrm{ab}}$ & $2,0 \pm 0,3^{\mathrm{a}}$ & $2,9 \pm 0,4^{\mathrm{a}}$ \\
\hline SP-\%0,5 & $97,5 \pm 8,5^{\mathrm{a}}$ & $355,0 \pm 9,0^{\mathrm{ab}}$ & $151,0 \pm 8,0^{\mathrm{a}}$ & $483,0 \pm 15,0^{\mathrm{ab}}$ & $2,3 \pm 0,0^{\mathrm{a}}$ & $3,2 \pm 0,1^{\mathrm{a}}$ \\
\hline SP- $\% 0,75$ & $88,5 \pm 1,5^{\mathrm{a}}$ & $344,0 \pm 11,0^{\mathrm{ab}}$ & $146,0 \pm 6,0^{\mathrm{a}}$ & $450,5 \pm 12,5^{\mathrm{ab}}$ & $2,3 \pm 0,1^{\mathrm{a}}$ & $3,1 \pm 0,2^{\mathrm{a}}$ \\
\hline SP-\%1,0 & $84,5 \pm 5,5^{\mathrm{a}}$ & $328,0 \pm 11,0^{\mathrm{ab}}$ & $152,0 \pm 7,0^{\mathrm{a}}$ & $410,5 \pm 17,5^{b}$ & $2,1 \pm 0,0^{\mathrm{a}}$ & $2,7 \pm 0,0^{\mathrm{a}}$ \\
\hline \multicolumn{7}{|c|}{135 Dakika } \\
\hline Kontrol & $96,0 \pm 9,0^{\mathrm{a}}$ & $378,5 \pm 42,5^{\mathrm{a}}$ & $141,0 \pm 2,0^{\mathrm{a}}$ & $515,0 \pm 40,0^{\mathrm{a}}$ & $2,6 \pm 0,2^{\mathrm{a}}$ & $3,6 \pm 0,2^{\mathrm{a}}$ \\
\hline SP-\%0,25 & $105,0 \pm 1,0^{\mathrm{a}}$ & $300,5 \pm 2,5^{b}$ & $174,5 \pm 9,5^{\mathrm{a}}$ & $451,5 \pm 10,5^{\mathrm{ab}}$ & $1,7 \pm 0,0^{\mathrm{b}}$ & $2,6 \pm 0,0^{\mathrm{b}}$ \\
\hline SP-\%0,5 & $92,0 \pm 1,0^{\mathrm{a}}$ & $335,5 \pm 6,5^{\mathrm{ab}}$ & $152,5 \pm 3,5^{\mathrm{a}}$ & $448,0 \pm 4,0^{\mathrm{ab}}$ & $2,2 \pm 0,1^{\mathrm{ab}}$ & $2,9 \pm 0,1^{\mathrm{ab}}$ \\
\hline SP-\%0,75 & $86,0 \pm 0,0^{\mathrm{a}}$ & $315,5 \pm 17,5^{\mathrm{b}}$ & $153,0 \pm 4,0^{\mathrm{a}}$ & $416,5 \pm 8,5^{a b}$ & $2,0 \pm 0,1^{\mathrm{ab}}$ & $2,7 \pm 0,1^{b}$ \\
\hline SP-\%1,0 & $78,5 \pm 5,5^{\mathrm{a}}$ & $326,0 \pm 5,0^{\mathrm{ab}}$ & $141,5 \pm 7,5^{\mathrm{a}}$ & $402,0 \pm 11,0^{\mathrm{b}}$ & $2,3 \pm 0,1^{\mathrm{ab}}$ & $2,8 \pm 0,0^{\mathrm{ab}}$ \\
\hline
\end{tabular}

SP: Spirulina platensis; B.U.: Brabender birimi; mm: milimetre. SP-\%0,25, SP-\%0,5 ve SP-\%0,75 ve SP-\%1,0: Sırasılyla \%0,25, \%0,5, \%0,75 ve \%1 oranında SP ilaveli un. Değerlerin istatistiksel analizleri 45, 90 ve 135. dakikalar için ayrı olarak gerçekleştirilmiştir. *a, b, c harfleri 45, 90 ve 135. dakikalardaki aynı sütun için istatistiksel olarak farklılığ ifade etmektedir ( $\mathrm{p}<0,05$, Tukey). 
Tablo 3. Spirulina platensis tozunun \%0,125, 0,25 ve 0,5 oranlarında ilave edildiği buğday unlarının 45,90 ve 135. dakikalarda ekstensogram değerleri.

\begin{tabular}{|c|c|c|c|c|c|c|}
\hline Örnek & $\begin{array}{l}\text { Enerji, } \\
\left(\mathrm{cm}^{2}\right)\end{array}$ & R5 (B.U.)* & Rmaks (B.U.) & $\begin{array}{c}\text { Esneklik } \\
\text { (mm) }\end{array}$ & $\begin{array}{c}\text { İşlenebilirlik } \\
\text { Oranı } \\
\text { (B.U./mm) }\end{array}$ & $\begin{array}{c}\text { Mak. } \\
\text { İşlenebilirlik } \\
\text { Oranı (B.U./mm) }\end{array}$ \\
\hline \multicolumn{7}{|c|}{ 45. dakika } \\
\hline Kontrol & $103,0 \pm 5,0^{\mathrm{a}^{*}}$ & $364,5 \pm 29,5^{\mathrm{a}}$ & $154,5 \pm 2,5^{\mathrm{ab}}$ & $493,0 \pm 31,0^{\mathrm{a}}$ & $2,3 \pm 0,2^{\mathrm{a}}$ & $3,2 \pm 0,2^{\mathrm{a}}$ \\
\hline SP-\%0,125 & $102,0 \pm 3,0^{\mathrm{a}}$ & $349,5 \pm 0,5^{\mathrm{a}}$ & $156,5 \pm 2,5^{\mathrm{a}}$ & $480,0 \pm 6,0^{\mathrm{a}}$ & $2,2 \pm 0,0^{\mathrm{a}}$ & $3,1 \pm 0,0^{\mathrm{a}}$ \\
\hline SP-\%0,25 & $98,5 \pm 4,5^{\mathrm{a}}$ & $350,5 \pm 1,5^{\mathrm{a}}$ & $147,0 \pm 1,0^{\mathrm{ab}}$ & $478,5 \pm 6,5^{\mathrm{a}}$ & $2,4 \pm 0,0^{\mathrm{a}}$ & $3,2 \pm 0,0^{\mathrm{a}}$ \\
\hline SP-\%0,5 & $101,0 \pm 1,0^{\mathrm{a}}$ & $392,0 \pm 1,0^{\mathrm{a}}$ & $143,5 \pm 1,5^{\mathrm{b}}$ & $507,5 \pm 8,5^{\mathrm{a}}$ & $2,7 \pm 0,0^{\mathrm{a}}$ & $3,5 \pm 0,0^{\mathrm{a}}$ \\
\hline \multicolumn{7}{|c|}{ 90. dakika } \\
\hline Kontrol & $110,0 \pm 6,0^{\mathrm{a}}$ & $491,0 \pm 26,0^{\mathrm{a}}$ & $132,0 \pm 2,0^{\mathrm{b}}$ & $640,0 \pm 21,0^{\mathrm{a}}$ & $3,7 \pm 0,1^{\mathrm{a}}$ & $4,8 \pm 0,0^{\mathrm{a}}$ \\
\hline SP-\%0,125 & $123,5 \pm 2,5^{\mathrm{a}}$ & $496,0 \pm 21,0^{\mathrm{a}}$ & $140,0 \pm 1,0^{\mathrm{a}}$ & $679,5 \pm 17,5^{a}$ & $3,5 \pm 0,1^{\mathrm{ab}}$ & $4,8 \pm 0,1^{\mathrm{a}}$ \\
\hline SP-\%0,25 & $118,5 \pm 0,5^{\mathrm{a}}$ & $429,5 \pm 4,5^{\mathrm{a}}$ & $145,0 \pm 0,0^{\mathrm{a}}$ & $623,5 \pm 2,5^{\mathrm{a}}$ & $2,9 \pm 0,0^{\mathrm{b}}$ & $4,3 \pm 0,0^{\mathrm{b}}$ \\
\hline SP-\%0,5 & $128,0 \pm 1,0^{\mathrm{a}}$ & $485,0 \pm 5,0^{\mathrm{a}}$ & $146,5 \pm 0,5^{\mathrm{a}}$ & $677,5 \pm 5,5^{\mathrm{a}}$ & $3,3 \pm 0,0^{\mathrm{ab}}$ & $4,6 \pm 0,1^{\mathrm{ab}}$ \\
\hline \multicolumn{7}{|c|}{ 135. dakika } \\
\hline Kontrol & $118,5 \pm 3,5^{\mathrm{a}}$ & $521,0 \pm 14,0^{\mathrm{a}}$ & $132,0 \pm 0,0^{\mathrm{a}}$ & $702,0 \pm 19,0^{\mathrm{a}}$ & $3,9 \pm 0,0^{\mathrm{a}}$ & $5,3 \pm 0,1^{\mathrm{a}}$ \\
\hline SP-\%0,125 & $121,0 \pm 1,0^{\mathrm{a}}$ & $536,0 \pm 19,0^{\text {a }}$ & $133,5 \pm 2,5^{\mathrm{a}}$ & $696,5 \pm 2,5^{\mathrm{a}}$ & $4,0 \pm 0,2^{\mathrm{a}}$ & $5,2 \pm 0,1^{\mathrm{a}}$ \\
\hline SP-\%0,25 & $124,5 \pm 2,5^{\mathrm{a}}$ & $530,5 \pm 17,5^{\mathrm{a}}$ & $132,5 \pm 4,5^{\mathrm{a}}$ & $710,5 \pm 3,5^{\mathrm{a}}$ & $4,1 \pm 0,1^{\mathrm{a}}$ & $5,3 \pm 0,5^{\mathrm{a}}$ \\
\hline SP- $\% 0,5$ & $131,5 \pm 2,5^{\mathrm{a}}$ & $550,5 \pm 61,5^{\mathrm{a}}$ & $139,5 \pm 4,5^{\mathrm{a}}$ & $746,0 \pm 58,0^{\mathrm{a}}$ & $3,9 \pm 0,5^{\mathrm{a}}$ & $5,4 \pm 0,6^{\mathrm{a}}$ \\
\hline
\end{tabular}

SP: Spirulina platensis; B.U.: Brabender birimi; mm: milimetre. SP-\%0,125, SP-\%0,25ve SP-\%0,5: Sirasıly $\% 0,125, \% 0,25$ ve $\% 0,5$ oranında SP ilaveli un. Değerlerin istatistiksel analizleri 45, 90 ve 135. dakikalar için ayrı olarak gerçekleştirilmiştir. *a, b, c harfleri 45, 90 ve 135. dakikalardaki aynı sütun için istatistiksel olarak farklılığ ifade etmektedir ( $<<0,05$, Tukey).

Tablo 4. Spirulina platensis ve Spirulina platensis protein ekstraktlarının \%0,125, 0,25 ve 0,5 oranlarında ilave edildiği buğday unlarını 45, 90 ve 135. dakikalarda ekstensogram değerleri.

\begin{tabular}{|c|c|c|c|c|c|c|}
\hline Örnek & $\begin{array}{l}\text { Enerji } \\
\left(\mathbf{c m}^{2}\right)\end{array}$ & $\mathbf{R}_{5}$ (B.U.)* & $\begin{array}{l}R_{\text {mak }} \\
\text { (B.U.) }\end{array}$ & $\begin{array}{l}\text { Esneklik } \\
\text { (mm) }\end{array}$ & $\begin{array}{l}\text { İşlenebilirlik } \\
\text { Oranı } \\
\text { (B.U./mm) }\end{array}$ & $\begin{array}{l}\text { Mak. } \\
\text { İşlenebilirlik } \\
\text { Oranı } \\
\text { (B.U./mm) }\end{array}$ \\
\hline \multicolumn{7}{|c|}{ 45.dakika } \\
\hline Kontrol & $121,0 \pm 1,0^{*}$ & $491,0 \pm 23,0$ & $139,5 \pm 2,5$ & $695,5 \pm 0,5$ & $3,5 \pm 0,3$ & $4,9 \pm 0,1$ \\
\hline SP-\%0,125 & $119,0 \pm 2,0$ & $489,0 \pm 11,0$ & $136,5 \pm 1,5$ & $687,5 \pm 43,5$ & $3,6 \pm 0,3$ & $4,8 \pm 0,1$ \\
\hline SP- $\% 0,25$ & $122,5 \pm 2,5$ & $506,5 \pm 42,5$ & $137,0 \pm 4,0$ & $725,0 \pm 0,0$ & $3,7 \pm 0,4$ & $5,3 \pm 0,1$ \\
\hline SP-\%0,5 & $120,5 \pm 0,5$ & $519,0 \pm 9,0$ & $136,5 \pm 1,5$ & $706,0 \pm 2,0$ & $3,9 \pm 0,1$ & $5,3 \pm 0,1$ \\
\hline SPE- $\% 0,125$ & $120,0 \pm 1,0$ & $464,5 \pm 8,5$ & $137,5 \pm 1,5$ & $675,5 \pm 22,5$ & $3,3 \pm 0,1$ & $4,8 \pm 0,0$ \\
\hline SPE- $\% 0,25$ & $120,0 \pm 0,0$ & $472,0 \pm 50,0$ & $137,5 \pm 1,5$ & $671,0 \pm 25,0$ & $3,4 \pm 0,4$ & $4,9 \pm 0,2$ \\
\hline SPE- $\% 0,5$ & $122,5 \pm 0,5$ & $475,0 \pm 7,0$ & $141,0 \pm 1,0$ & $694,5 \pm 0,5$ & $3,3 \pm 0,1$ & $4,8 \pm 0,0$ \\
\hline \multicolumn{7}{|c|}{ 90. dakika } \\
\hline Kontrol & $135,0 \pm 1,0$ & $1002,5 \pm 11,5$ & $106,0 \pm 1,0$ & $1111,5 \pm 26,5$ & $9,4 \pm 0,2$ & $10,5 \pm 0,4$ \\
\hline SP-\%0,125 & $133,5 \pm 2,5$ & $1012,0 \pm 2,0$ & $105,0 \pm 0,0$ & $1125,5 \pm 18,5$ & $9,7 \pm 0,0$ & $10,7 \pm 0,2$ \\
\hline SP- $\% 0,25$ & $128,5 \pm 0,5$ & $1070,5 \pm 73,5$ & $100,0 \pm 0,0$ & $1122,0 \pm 23,0$ & $10,7 \pm 0,7$ & $11,2 \pm 0,2$ \\
\hline SP-\%0,5 & $125,0 \pm 4,0$ & $975,5 \pm 29,5$ & $101,0 \pm 4,0$ & $1088,5 \pm 16,5$ & $9,8 \pm 0,8$ & $10,9 \pm 0,7$ \\
\hline SPE-\%0,125 & $128,0 \pm 0,0$ & $1018,5 \pm 11,5$ & $102,0 \pm 0,0$ & $1116,5 \pm 7,5$ & $9,9 \pm 0,1$ & $10,9 \pm 0,5$ \\
\hline SPE-\%0,25 & $129,5 \pm 2,5$ & $935,5 \pm 14,5$ & $108,5 \pm 1,5$ & $1068,5 \pm 5,5$ & $8,6 \pm 0,2$ & $9,8 \pm 0,2$ \\
\hline SPE- $\% 0,5$ & $129,0 \pm 1,0$ & $1005,5 \pm 14,5$ & $104,5 \pm 2,5$ & $1083,0 \pm 2,0$ & $9,6 \pm 0,4$ & $10,3 \pm 0,2$ \\
\hline \multicolumn{7}{|c|}{ 135. dakika } \\
\hline Kontrol & $130,5 \pm 0,5$ & $1091,0 \pm 16,0$ & $104,0 \pm 3,0$ & $1113,0 \pm 6,0$ & $10,5 \pm 0,4$ & $10,7 \pm 0,2$ \\
\hline SP-\%0,125 & $129,0 \pm 2,0$ & $1018,0 \pm 32,0$ & $108,0 \pm 5,0$ & $1079,5 \pm 22,5$ & $9,4 \pm 0,8$ & $10,0 \pm 0,8$ \\
\hline $\begin{array}{l}\text { SP- } \% 0,25 \\
\end{array}$ & $130,5 \pm 4,5$ & $1018,0 \pm 32,0$ & $110,5 \pm 1,5$ & $1106,5 \pm 20,5$ & $9,2 \pm 0,3$ & $10,0 \pm 0,3$ \\
\hline SP-\%0,5 & $126,5 \pm 2,5$ & $1079,0 \pm 4,0$ & $101,0 \pm 2,0$ & $1111,5 \pm 2,5$ & $10,7 \pm 0,3$ & $11,0 \pm 0,2$ \\
\hline SPE- $\% 0,125$ & $126,5 \pm 3,5$ & $1007,0 \pm 15,0$ & $104,0 \pm 1,0$ & $1066,0 \pm 16,0$ & $9,6 \pm 0,2$ & $10,2 \pm 0,2$ \\
\hline SPE- $\% 0,25$ & $129,0 \pm 2,0$ & $961,0 \pm 56,0$ & $106,0 \pm 1,0$ & $1100,0 \pm 70,0$ & $9,1 \pm 0,6$ & $10,4 \pm 0,8$ \\
\hline SPE- $\% 0,5$ & $125,5 \pm 1,5$ & $1109,0 \pm 2,0$ & $99,0 \pm 2,0$ & $1119,5 \pm 12,5$ & $11,3 \pm 0,3$ & $11,4 \pm 0,4$ \\
\hline
\end{tabular}

Herbir değer ortalama \pm standart sapma olarak verilmiştir $(\mathrm{n}=3)$. SP: Spirulina platensis tozu, SPE: Spirulina platensis protein ekstraktı. SP-\%0, 125, SP-\%0, 25 ve SP-\%0,50: Sirasıyla $\% 0,125, \% 0,25$ ve $\% 0,5$ oranında SP ilaveli un. SPE- $\% 0,125$, SPE- $\% 0,25$ ve SPE- $\% 0,50$ : Sirasıyla $\% 0,125, \% 0,25$ ve \%0,5 oranında SPE ilaveli un. *: İstatistiksel olarak fark olmadığı için harf belirtilmemiştir. 
Tablo 5. Spirulina platensis ve Spirulina platensis protein ekstraktlarının \%0,125, 0,25 ve 0,5 oranlarında ilave edildiği buğday unlarınin farinogram değerleri.

\begin{tabular}{|l|c|c|c|c|c|}
\hline Örnek & $\begin{array}{c}\text { Su Absorbsiyonu } \\
\mathbf{\%}\end{array}$ & $\begin{array}{c}\text { Gelişme Süresi } \\
(\mathbf{d a k})\end{array}$ & $\begin{array}{c}\text { Stabilite Değeri } \\
(\mathbf{d a k})\end{array}$ & $\begin{array}{c}\text { Yumuşama Derecesi } \\
(\mathbf{1 0 . d a k})\end{array}$ & $\begin{array}{c}\text { Yumuşama } \\
\text { Derecesi } \\
(\mathbf{1 2 .} \text { dak) }\end{array}$ \\
\hline Kontrol & $56,5 \pm 0,0^{\mathrm{b}^{*}}$ & $1,8 \pm 0,0^{\mathrm{a}}$ & $2,0 \pm 0,0^{\mathrm{a}}$ & $83,5 \pm 3,5^{\mathrm{a}}$ & $84,5 \pm 1,5^{\mathrm{a}}$ \\
\hline SP-\%0,125 & $56,5 \pm 0,0^{\mathrm{b}}$ & $1,7 \pm 0,0^{\mathrm{a}}$ & $1,9 \pm 0,0^{\mathrm{a}}$ & $85,5 \pm 1,5^{\mathrm{a}}$ & $89,0 \pm 1,0^{\mathrm{a}}$ \\
\hline SP-\%0,25 & $56,9 \pm 0,1^{\mathrm{ab}}$ & $1,9 \pm 0,1^{\mathrm{a}}$ & $2,0 \pm 0,1^{\mathrm{a}}$ & $82,5 \pm 3,5^{\mathrm{a}}$ & $85,0 \pm 0,0^{\mathrm{a}}$ \\
\hline SP-\%0,5 & $57,1 \pm 0,0^{\mathrm{a}}$ & $1,6 \pm 0,0^{\mathrm{a}}$ & $1,7 \pm 0,0^{\mathrm{a}}$ & $82,0 \pm 2,0^{\mathrm{a}}$ & $90,0 \pm 1,0^{\mathrm{a}}$ \\
\hline SPE-\%0,125 & $56,6 \pm 0,0^{\mathrm{b}}$ & $1,7 \pm 0,0^{\mathrm{a}}$ & $1,9 \pm 0,0^{\mathrm{a}}$ & $86,0 \pm 4,0^{\mathrm{a}}$ & $85,0 \pm 1,0^{\mathrm{a}}$ \\
\hline SPE-\%0,25 & $56,7 \pm 0,0^{\mathrm{b}}$ & $1,7 \pm 0,0^{\mathrm{a}}$ & $1,9 \pm 0,0^{\mathrm{a}}$ & $87,0 \pm 3,0^{\mathrm{a}}$ & $88,0 \pm 3,0^{\mathrm{a}}$ \\
\hline SPE-\%0,5 & $56,8 \pm 0,1^{\mathrm{ab}}$ & $1,7 \pm 0,0^{\mathrm{a}}$ & $1,9 \pm 0,1^{\mathrm{a}}$ & $88,5 \pm 0,5^{\mathrm{a}}$ & $92,0 \pm 0,0^{\mathrm{a}}$ \\
\hline
\end{tabular}

Herbir değer ortalama \pm standart sapma olarak verilmiştir $(\mathrm{n}=3)$. SP: Spirulina platensis tozu, SPE: Spirulina platensis protein ekstraktı. SP- $\% 0,125$, SP- $\% 0,25$ ve SP- $\% 0,50$ : Sirasiyla $\% 0,125, \% 0,25$ ve $\% 0,5$ oranında SP ilaveli un. SPE- $\% 0,125$, SPE- $\% 0,25$ ve SPE- $\% 0,50$ : Sirasıyla $\% 0,125, \% 0,25$ ve $\% 0,5$ oranında SPE ilaveli un. *: Kolondaki farklı harfler, Tukey testi tarafindan istatistiksel olarak $(\mathrm{p}<0,05)$ farklılı̆̆ 1 ifade etmektedir.

\subsection{Kontrol ile SP ve SPE ilaveli unların fizikokimyasal özellikleri}

Un kalitesinin belirlenmesinde kullanılan en önemli özelliklerden biri de undaki gluten (öz) miktarıdır. Unda bulunan gluten proteini, maya tarafindan oluşturulan $\mathrm{CO}_{2}$ gazının ağ yapı içinde tutunmasını ve böylece hamurun kabarmasını sağlamaktadır (Servet ve Akman, 2014). Unun gluten miktarı ve kalitesi hamurun gaz tutma kapasitesinin yanı sıra yoğrulma ve işlenme özellikleri ile son ürün kalitesi üzerinde de doğrudan etkilidir (Kent, 1984). Kontrol örneği ve SP ve SPE ilaveli unların yaş gluten, gluten indeksi, kuru gluten, normal sedimentasyon ve gecikmeli sedimentasyon değerleri Tablo 6'da verilmiştir. Örneklerin yaş gluten, gluten indeksi ve kuru gluten değerleri ile normal ve gecikmeli sedimantasyon değerleri arasındaki farklılık istatistiksel olarak önemli değildir ( $\mathrm{p} \geq 0,05)$.

Sunulan çalışmada, un örneklerinin normal sedimentasyon değeri 27,5 ile $28,5 \mathrm{ml}$ olarak bulunmuşken, gecikmeli sedimentasyon değeri 35,5-37,0 $\mathrm{ml}$ arasında değişmiştir (Tablo 6). Słowik (2006)'e göre $>40 \mathrm{ml}$ sedimentasyon değerine sahip un, çok iyi kalitede un olarak tanımlanmıştır. Ayrıca, 30-40 ml sedimentasyon değerindeki unlar iyi, 20-29 ml sedimentasyon değerindeki unlar yeterli kalitede ve $<20 \mathrm{ml}$ sedimentasyon değerindeki unlar düşük kalitede unlar olarak sınıflandırılmıştır (Słowik, 2006). Çalışmamızda kullandığımız tüm un örneklerinin normal sedimentasyon değerinin $25-30 \mathrm{ml}$ arasında olması unların iyi kalitede olduğunu göstermektedir.

\subsection{Kontrol ve SP ve SPE ilaveli unların teknofonksiyonel özellikleri}

Unun su tutma kapasitesi hamurun reolojik özellikleri ve son ürünün kalitesini etkilediğinden ekmek yapım özellikleri üzerinde etkili olan faktörlerden biridir ve su tutma kapasitesi unda bulunan gluten proteininin miktarı ve kalitesi ile undaki zedelenmiş nişasta ve liflerin miktarına bağlı olarak değişmektedir (Du ve ark., 2014). Ayrıca, su tutma kapasitesi ekmek içinin yumuşaklığı ve ekmek özelliklerinin korunması üzerinde de etkili olan faktörlerdendir (Koppel ve Ingver, 2010). Tablo 7'de kontrol ve zenginleștirilmiş un örneklerinin su tutma ve yağ tutma kapasiteleri ile yığın yoğunluğu ve şişme indeksi değerleri verilmiştir. Çalışmamızda örneklerin su tutma kapasitesi, Tablo 7 'de görüldüğü gibi, $\% 90,23 \pm 0,57$ ile $\% 108,68 \pm 5,82$ arasında

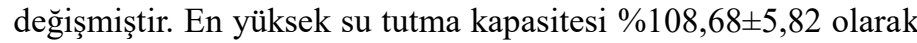
$\% 0,125$ S. platensis protein ekstraktı ile zenginleştirilmiş unlarda, en düşük su tutma kapasitesi ise $\% 90,23 \pm 0,57, \% 91,55 \pm 0,42$ ve $\% 91,64 \pm 1,10$ olarak sirasiyla SP-\%0,25, SP-\%0,5 ve kontrol örneklerinde gerçekleşmiştir $(\mathrm{p}<0,05)$. Kontrol örneğinin su tutma kapasitesi $(\% 91,64 \pm 1,10) ; \quad$ SP-\%0,125 $(\% 98,11 \pm 1,62)$,

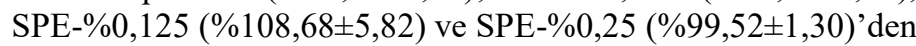
istatistiksel olarak önemli düzeyde daha düşüktür $(p<0,05)$. Çalışmamızda elde ettiğimiz değerlere yakın olarak Bashir ve ark. (2017)'nın çalışmasında buğday ununun su tutma kapasitesi \%85 olarak belirlenmiştir. Çalışmamızdan farklı olarak buğday ununun su tutma kapasitesini Das ve ark. (2019) \%66,59, Nwosu ve ark. (2014) ise \%207 olarak tespit etmiştir.

Tablo 7'de görüldüğü gibi, örneklerin yağ tutma kapasitesi en düşük kontrol örneğinde $\% 88,91 \pm 0,88$ ve SP $\% 0,25$ 'de $\% 86,60 \pm 1.40$ olarak ve en yüksek SPE- $\% 0,25$ örneğinde $\% 107,39 \pm 1,86$ olarak belirlenmiştir $(\mathrm{p} \geq 0,05)$. Nwosu ve ark. (2014), buğday ununun yağ tutma kapasitesini \%152 olarak belirlerken, Bashir ve ark. (2017), tam buğday ununun yağ tutma kapasitesini çalışmamızda elde ettiğimiz değerlere yakın olarak \%110 olarak tespit etmiştir.

Çalışmamızda, örneklerin yığın yoğunluğu değeri 0,54 ile 0,65 $\mathrm{g} / \mathrm{ml}$ arasında değişmiştir ve örneklerin yığın yoğunluğu değerleri arasındaki farklılık istatistiksel olarak önemli düzeyde değildir ( $\mathrm{p} \geq 0,05$, Tablo 7). Çalışmamıza benzer olarak Siddiq ve ark. (2010)'nın çalışmasında, kurutulmuş fasulye unlarının yı ğın yoğunluğu değerleri $0,515-0,556 \mathrm{~g} / \mathrm{ml}$ arasında değişmiştir. Nwosu ve ark. (2014), buğday ununun yığın yoğunluğunu 0,70 $\mathrm{g} / \mathrm{ml}$ olarak belirlemiştir. Benzer olarak, Bashir ve ark. (2017) da tam buğday ununun yığın yoğunluğunu $0,77 \mathrm{~g} / \mathrm{ml}$ olarak belirlemiştir. 
Tablo 6. Spirulina platensis ve Spirulina platensis protein ekstraktlarının \%0,125, 0,25 ve 0,5 oranlarında ilave edildiği buğday unlarının normal sedimentasyon, gecikmeli sedimentasyon, yaş gluten, gluten indeksi ve kuru gluten değerleri.

\begin{tabular}{|l|c|c|c|c|c|}
\hline \multicolumn{1}{|c|}{ Örnek } & $\begin{array}{c}\text { Normal } \\
\text { sedimentasyon }(\mathbf{m l})\end{array}$ & $\begin{array}{c}\text { Gecikmeli } \\
\text { sedimentasyon } \\
(\mathbf{m l})\end{array}$ & Yaş gluten (\%) & $\begin{array}{c}\text { Gluten indeksi } \\
\mathbf{( \% )}\end{array}$ & $\begin{array}{c}\text { Kuru gluten } \\
(\mathbf{m l})\end{array}$ \\
\hline Kontrol & $28,5 \pm 0,5^{*}$ & $35,5 \pm 0,5$ & $27,5 \pm 0,2$ & $93,5 \pm 0,9$ & $9,3 \pm 0,1$ \\
\hline SP-\%0,125 & $28,0 \pm 0,0$ & $36,5 \pm 0,5$ & $27,5 \pm 0,1$ & $93,1 \pm 0,7$ & $9,3 \pm 0,1$ \\
\hline SP-\%0,25 & $28,5 \pm 0,5$ & $36,5 \pm 0,5$ & $27,6 \pm 0,1$ & $93,6 \pm 0,3$ & $9,4 \pm 0,2$ \\
\hline SP-\%0,5 & $28,0 \pm 0,0$ & $37,0 \pm 0,0$ & $27,6 \pm 0,1$ & $94,6 \pm 0,4$ & $9,4 \pm 0,1$ \\
\hline SPE-\%0,125 & $27,5 \pm 0,5$ & $36,5 \pm 0,5$ & $27,4 \pm 0,1$ & $94,0 \pm 0,5$ & $9,3 \pm 0,1$ \\
\hline SPE-\%0,25 & $28,0 \pm 0,0$ & $36,0 \pm 0,0$ & $27,3 \pm 0,1$ & $93,1 \pm 0,4$ & $9,3 \pm 0,0$ \\
\hline SPE-\%0,5 & $28,5 \pm 0,5$ & $35,5 \pm 0,5$ & $27,6 \pm 0,2$ & $94,4 \pm 0,3$ & $9,4 \pm 0,0$ \\
\hline
\end{tabular}

Herbir değer ortalama \pm standart sapma olarak verilmiștir $(\mathrm{n}=3)$. SP: Spirulina platensis tozu, SPE: Spirulina platensis protein ekstraktı. SP-\%0,125, SP-\%0,25 ve SP-\%0,50: Sirasiyla \%0,125, \%0,25 ve \%0,5 oranında SP ilaveli un. SPE- $\% 0,125$, SPE- $\% 0,25$ ve SPE- $\% 0,50$ : Sirasıyla $\% 0,125, \% 0,25$ ve $\% 0,5$ oranında SPE ilaveli un. *: İstatistiksel olarak fark olmadığ 1 için harf belirtilmemiştir.

Tablo 7. Spirulina platensis ve Spirulina platensis protein ekstraktlarının \%0,125, 0,25 ve 0,5 oranlarında ilave edildiği buğday unlarının su tutma kapasitesi, yağ tutma kapasitesi, yığın yoğunluğu ve şişme indeksi değerleri.

\begin{tabular}{|l|l|l|l|l|}
\hline Örnek & $\begin{array}{l}\text { Su tutma kapasitesi, } \\
\mathbf{\%}\end{array}$ & $\begin{array}{l}\text { Yă̆ tutma kapasitesi, } \\
\mathbf{\%}\end{array}$ & $\begin{array}{l}\text { Yı̆̆ın yoğunluğu, } \\
\text { g/ml }\end{array}$ & Şişme indeksi, ml \\
\hline Kontrol & $91,64 \pm 1,10^{\mathrm{b}}$ & $88,91 \pm 0,88^{\mathrm{a}}$ & $0,61 \pm 0,03^{\mathrm{a}}$ & $1,36 \pm 0,1^{\mathrm{a}}$ \\
\hline SP-\%0,125 & $98,11 \pm 1,62^{\mathrm{ab}}$ & $91,59 \pm 0,66^{\mathrm{a}}$ & $0,65 \pm 0,03^{\mathrm{a}}$ & $1,32 \pm 0,0^{\mathrm{a}}$ \\
\hline SP-\%0,25 & $90,23 \pm 0,57^{\mathrm{b}}$ & $86,60 \pm 1,40^{\mathrm{a}}$ & $0,64 \pm 0,01^{\mathrm{a}}$ & $1,32 \pm 0,0^{\mathrm{a}}$ \\
\hline SP-\%0,5 & $91,55 \pm 0,42^{\mathrm{b}}$ & $89,03 \pm 7,04^{\mathrm{a}}$ & $0,59 \pm 0,04^{\mathrm{a}}$ & $1,32 \pm 0,0^{\mathrm{a}}$ \\
\hline SPE-\%0,125 & $108,68 \pm 5,82^{\mathrm{a}}$ & $99,77 \pm 6,30^{\mathrm{a}}$ & $0,62 \pm 0,02^{\mathrm{a}}$ & $1,33 \pm 0,0^{\mathrm{a}}$ \\
\hline SPE-\%0,25 & $99,52 \pm 1,30^{\mathrm{ab}}$ & $107,39 \pm 1,86^{\mathrm{a}}$ & $0,54 \pm 0,04^{\mathrm{a}}$ & $1,57 \pm 0,0^{\mathrm{a}}$ \\
\hline SPE-\%0,5 & $94,93 \pm 0,60^{\mathrm{b}}$ & $91,56 \pm 1,21^{\mathrm{a}}$ & $0,61 \pm 0,03^{\mathrm{a}}$ & $1,45 \pm 0,1^{\mathrm{a}}$ \\
\hline
\end{tabular}

Herbir değer ortalama \pm standart sapma olarak verilmiştir $(\mathrm{n}=3)$. SP: Spirulina platensis tozu, SPE: Spirulina platensis protein ekstraktı, SP-\%0,125, SP-\%0,25 ve SP-\%0,50: Sirasiyla \%0,125, \%0,25 ve \%0,5 oranında SP ilaveli un. SPE- $\% 0,125$, SPE- $\% 0,25$ ve SPE- $\% 0,50$ : Sirasiyla $\% 0,125, \% 0,25$ ve $\% 0,5$ oranında SPE ilaveli un. *: Kolondaki farklı harfler, Tukey testi tarafından istatistiksel olarak $(\mathrm{p}<0,05)$ farklılı̆̆ ifade etmektedir.

Çalışmamızda, örneklerin şişme indeksi 1,32 ile 1,57 arasında değişmiştir ( $\mathrm{p} \geq 0,05)$. Bashir ve ark. (2017) tam buğday ununun şişme indeksi değerini $50{ }^{\circ} \mathrm{C}$ 'den $90{ }^{\circ} \mathrm{C}$ 'ye değişen sicaklık uygulamalarında 1,83 ile $7,83 \mathrm{~g} / \mathrm{g}$ arasında değiştiğini belirlemiştir. Çalışmamızdan farklı olarak, Nwosu ve ark. (2014), buğday ununun şişme indeksi değerini 3,80 olarak tespit etmiştir. Das ve ark. (2019)'nın çalışmasında ise mango çekirdek ununun şişme indeksi $0,63 \mathrm{~g} / \mathrm{ml}$, buğday ununun $0,58 \mathrm{~g} / \mathrm{ml}$ olarak belirlenmiştir.

\section{Sonuç}

Spirulina platensis mikroalgi yüksek protein içeriği nedeni ile önemli bir gıda kaynağıdır. Bu çalışmada Spirulina platensis ve Spirulina platensis protein ekstraktları ile zenginleştirilmiş buğday ununun bazı reolojik ve teknofonksiyonel özelliklerinin yanı sıra fizikokimyasal özellikleri araştırılmıştır. Çalışmanın sonuçlarına göre SP-\%0,125, SPE-\%0,125 ve SPE-\%0,25'de su tutma kapasitenin kontrol örneğine göre daha yüksek olduğu görülmektedir. Gelecek çalışmalar, Spirulina platensis ve Spirulina platensis protein ekstraktlarının farklı oranlarda katılması ile elde edilen zenginleştirilmiş unların diğer reolojik ve teknofonksiyonel özelliklerinin de iyileştirilmesi çalışmaları gerçekleştirilebilr.

\section{Kaynakça}

Abbasi, H., Ardabili, S. M. S., Emam-Djomeh, Z. A. H. R. A., Mohammadifar, M. A., Zekri, M., \& Aghagholizadeh, R. (2012). Prediction of extensograph properties of wheat-flour e-ISSN: 2148-2683 dough: artificial neural networks and a genetic algorithm approach. Journal of Texture Studies, 43(4), 326-337.

Abd El Baky, H. H., El Baroty, G. S., \& Ibrahem, E. A. (2015). Functional characters evaluation of biscuits sublimated with pure phycocyanin isolated from Spirulina and Spirulina biomass. Nutricion Hospitalaria, 32(1), 231-241.

Ak, B., Avsaroglu, E., Isik, O., Özyurt, G., Kafkas, E., \& Etyemez, M. (2016). Nutritional and physicochemical characteristics of bread enriched with microalgae Spirulina platensis. International Journal of Engineering Research and Applications, 6(9).

American Association of Cereal Chemists. Approved Methods Committee. (2000). Approved methods of the American association of cereal chemists (Vol. 1). American Association of Cereal Chemists

American Association of Cereal Chemists. Approved Methods Committee. (2000). Approved Methods of the AACC, 10th ed., The Association:. Methods No: 54-21, 38-21A. St. Paul MN, USA

Bashir, K., Swer, T. L., Prakash, K. S., \& Aggarwal, M. (2017). Physico-chemical and functional properties of gamma irradiated whole wheat flour and starch. LWT-Food Science and Technology, 76, 131-139.

Benelhadj, S., Gharsallaoui, A., Degraeve, P., Attia, H. ve Ghorbel, D. (2016). Effect of $\mathrm{pH}$ on the functional properties of Arthrospira (Spirulina) platensis protein isolate. Food Chemistry, 194, 1056-1063.

Bermejo, P., Pinero, E., \& Villar, A. M. (2008). Iron-chelating ability and antioxidant properties of phycocyanin isolated from a protean extract of Spirulina platensis. Food 
Chemistry, $\quad 110(2), \quad 436-445 . \quad$ doi: 10.1016/j.foodchem.2008.02.021

Burešová, I., Kráčmar, S., Dvořáková, P., \& Středa, T. (2014). The relationship between rheological characteristics of gluten-free dough and the quality of biologically leavened bread. Journal of Cereal Science, 60(2), 271-275.

Chamorro-Cevallos, G., Garduño-Siciliano, L., Barrón, B. L., Madrigal-Bujaidar, E., Cruz-Vega, D. E., \& Pages, N. (2008). Chemoprotective effect of Spirulina (Arthrospira) against cyclophosphamide-induced mutagenicity in mice. Food and Chemical Toxicology, 46(2), 567-574.

Das, P. C., Khan, M. J., Rahman, M. S., Majumder, S., \& Islam, M. N. (2019). Comparison of the physico-chemical and functional properties of mango kernel flour with wheat flour and development of mango kernel flour based composite cakes. NFS journal, 17, 1-7.

De Marco, E. R., Steffolani, M. E., Martínez, C. S., \& León, A. E. (2014). Effects of Spirulina biomass on the technological and nutritional quality of bread wheat pasta. LWT-Food Science and tTchnology, 58(1), 102-108.

Du, S. K., Jiang, H., Yu, X., \& Jane, J. L. (2014). Physicochemical and functional properties of whole legume flour. LWT-Food Science and Technology, 55(1), 308-313.

El-Tantawy, W. H. (2015). Antioxidant effects of Spirulina supplement against lead acetate-induced hepatic injury in rats. Journal of Traditional and Complementary Medicine.

Estrada, J. P., Bescós, P. B., \& Del Fresno, A. V. (2001). Antioxidant activity of different fractions of Spirulina platensis protean extract. Il Farmaco, 56(5-7), 497-500.

Gad, A. S., Khadrawy, Y. A., El-Nekeety, A. A., Mohamed, S. R., Hassan, N. S., \& Abdel-Wahhab, M. A. (2011). Antioxidant activity and hepatoprotective effects of whey protein and Spirulina in rats. Nutrition, 27(5), 582-589.

Giami, S. Y., \& Bekebain, D. A. (1992). Proximate composition and functional properties of raw and processed full-fat fluted pumpkin (Telfairia occidentalis) seed flour. Journal of the Science of Food and Agriculture, 59(3), 321-325.

Karababa, E., \& Ozan, A. N. (1998). Effect of wheat bug (Eurygaster integriceps) damage on quality of a wheat variety grown in Turkey. Journal of the Science of Food and Agriculture, 77(3), 399-403.

Kent, N. L. (1984). Cereals of the world: grain structure. Technology of Cereals, 1626.

Koppel, R., \& Ingver, A. (2010). Stability and predictability of baking quality of winter wheat. Agronomy Research, 8(3), 637-644.

Lee, J. Y., Kang, S. H., \& Kim, M. R. (2011). Changes in the quality characteristics and antioxidant activities of spirulina added bread during storage. Korean Journal of Food Preservation, 18(1), 111-118.

Miś, A., Grundas, S., Dziki, D., \& Laskowski, J. (2012). Use of farinograph measurements for predicting extensograph traits of bread dough enriched with carob fibre and oat wholemeal. Journal of Food Engineering, 108(1), 1-12.

Nwosu, J. N., Owuamanam, C. I., Omeire, G. C., \& Eke, C. C. (2014). Quality parameters of bread produced from substitution of wheat flour with cassava flour using soybean as an improver. American Journal of Research Communication, 2(3), 99-118.

Onuegbu, N.C., Ihediohanma, N.C., Odunze, O.F. ve Ojukwu, M. (2013). Efficiency of wheat: maize composite flour as affected by baking method in bread and cake production. Sky Journal of Food Science, 2 (8), 005-013.
Özkaya, H. (2005). Tahıl ve ürünleri analiz yöntemleri. Gıda Teknolojisi Derneği Yayınları.

Pelizer, L. H., de Carvalho, J. C. M., \& de Oliveira Moraes, I. (2015). Protein production by Arthrospira (Spirulina) platensis in solid state cultivation using sugarcane bagasse as support. Biotechnology Reports, 5, 70-76.

Ram, S., Dawar, V., Singh, R. P., \& Shoran, J. (2005). Application of solvent retention capacity tests for the prediction of mixing properties of wheat flour. Journal of Cereal Science, 42(2), 261-266.

Rothkaehl J., 2004. Determination of the rheological properties of dough from domestic wheat flour (in Polish). ZPZiP IBPRS. Warszawa, 2004.

Sarker, M. Z. I., Yamauchi, H., Kim, S. J., MATSUMURAENDO, C., Takigawa, S., Hashimoto, N., \& Noda, T. (2008). A farinograph study on dough characteristics of mixtures of wheat flour and potato starches from different cultivars. Food Science and Technology research, 14(2), 211-216.

Servet, Ö., \& Akman, Z. (2014). Yozgat ekolojik koşullarında bazı ekmeklik buğday çeşitlerinin verim ve kalite özelliklerinin belirlenmesi. Ziraat Fakültesi Dergisi, 10(1), 35-43.

Siddiq, M., Ravi, R., Harte, J. B., \& Dolan, K. D. (2010). Physical and functional characteristics of selected dry bean (Phaseolus vulgaris L.) flours. LWT-Food Science and Technology, 43(2), 232-237.

Słowik E., 2006. Determination of the quality of flour - the commonly used methods (in Polish). Przegląd Piekarski i Cukierniczy, 54(11), 14-18.

Stanic-Vucinic, D., Minic, S., Nikolic, M. R., \& Velickovic, T. C. (2018). Spirulina phycobiliproteins as food components and complements. Microalgal Biotechnology, 129-149.

Stojceska, V., \& Butler, F. (2008). Digitization of farinogram plots and estimation of mixing stability. Journal of Cereal Science, 48(3), 729-733.

Stone, A. K., Karalash, A., Tyler, R. T., Warkentin, T. D., \& Nickerson, M. T. (2015). Functional attributes of pea protein isolates prepared using different extraction methods and cultivars. Food Research International, 76, 31-38.

Vo, T., Ngo, D., \& Kim, S. (2016). Nutritional and pharmaceutical properties of microalgal Spirulina, Handbook of Marine Microalgae: Biotechnology Advances. Elsevier Inc, UK, 299-308.

Wang, L., Pan, B., Sheng, J., Xu, J., \& Hu, Q. (2007). Antioxidant activity of Spirulina platensis extracts by supercritical carbon dioxide extraction. Food Chemistry, 105(1), 36-41.

Yucetepe, A., Saroglu, O., Bildik, F., Ozcelik, B., \& DaskayaDikmen, C. (2018). Optimisation of ultrasound-assisted extraction of protein from Spirulina platensis using RSM. Czech Journal of Food Sciences, 36(1), 98-108.

Zelleny, L. (1947). A simple sedimentation test for estimating the bread-baking and gluten qualities of wheat flour. Cereal Chem., 24, 465-475. 